\title{
Anti-Staphylococcal and Antioxidant Properties of Crude Ethanolic Extracts of Macrofungi Collected from the Philippines
}

\author{
Christine May Gaylan'1, John Carlo Estebal' ${ }^{1}$, Ourlad Alzeus G. Tantengco ${ }^{2}$, Elena M. Ragragio'
}

\section{Christine May Gaylan', John Carlo Estebal', Ourlad Alzeus G. Tanteng $\mathrm{CO}^{2}$, Elena M. Ragragio $^{1}$}

'Department of Biology, College of Arts and Sciences, University of the Philippines Manila, Padre Faura Street, Ermita, Manila, PHILIPPINES. ${ }^{2}$ College of Medicine, University of the Philippines Manila, Pedro Gil Street, Ermita, Manila, PHILIPPINES.

Correspondence

\section{Elena M. Ragragio}

Department of Biology, College of Arts and Sciences, University of the Philippines Manila, Padre Faura St., Ermita, Manila, PHILIPPINES.

Phone no: 63-025265861

E-mail: lenmragragio@gmail.com

History

- Submission Date: 26-09-2017;

- Review completed: 27-10-2017;

- Accepted Date: 02-11-2017

DOI : 10.5530/pj.2018.1.19

Article Available online

http://www.phcogj.com/v10/i1

\section{Copyright}

(C) 2018 Phcog.Net. This is an openaccess article distributed under the terms of the Creative Commons Attribution 4.0 International license.

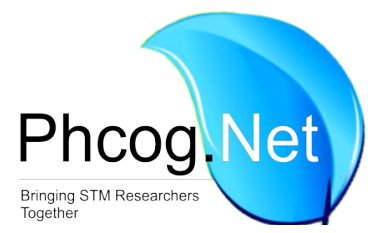

\begin{abstract}
Introduction: Macrofungi have been used in the Philippines as source of food and traditional medicines. However, these macrofungi in the Philippines have not yet been studied for different biological activities. Thus, this research determined the potential antibacterial and antioxidant activities of crude ethanolic extracts of seven macrofungi collected in Bataan, Philippines. Methods: Kirby-Bauer disk diffusion assay and broth microdilution method were used to screen for the antibacterial activity and DPPH scavenging assay for the determination of antioxidant activity. Results: F. rosea, G. applanatum, G. lucidum and P. pinisitus exhibited zones of inhibition ranging from $6.55 \pm 0.23 \mathrm{~mm}$ to $7.43 \pm 0.29 \mathrm{~mm}$ against $S$. aureus, $D$. confragosa, F. rosea, G. lucidum, M. xanthopus and $P$. pinisitus showed antimicrobial activities against $S$. aureus with an $\mathrm{MIC}_{50}$ ranging from $1250 \mu \mathrm{g} / \mathrm{mL}$ to $10000 \mu \mathrm{g} / \mathrm{mL}$. F. rosea, G. applanatum, G. lucidum, M. xanthopus exhibited excellent antioxidant activity with $F$. rosea having the highest antioxidant activity among all the extracts tested $(3.0 \mu \mathrm{g} / \mathrm{mL})$. Conclusion: Based on the results, these Philippine macrofungi showed antistaphylococcal activity independent of the antioxidant activity. These can be further studied as potential sources of antibacterial and antioxidant compounds.
\end{abstract}

Key words: Antimicrobial, Antioxidant, Mushrooms, Philippines, Staphylococcus aureus.

\section{INTRODUCTION}

Macrofungi have been used for a long time in traditional medicine especially in Asian countries. ${ }^{1}$ This indicated the potential presence of mycochemicals that are responsible for the health benefits of macrofungi. It has been previously reported that constituent compounds of macrofungi have cytotoxic, antinociceptic, and immunomodulatory properties. ${ }^{2,3,4}$

Alternative antibacterials and antioxidants have been found in compounds from the environment. The growing potentials of mushrooms have also encompassed such properties as it has been confirmed that its chemical components also have antibacterial ${ }^{5}$ and antioxidant activities by radical and metal-scavenging. ${ }^{6}$ Despite these literatures, there are not much published work on the antibacterial and antioxidant activities of the mushrooms in the Philippines as there is a lack of documentation on Philippine local mushrooms in general. ${ }^{7}$

The aim of this study was to determine the antibacterial and antioxidant activities of crude ethanolic extracts of Daedaleopsis confragosa (Bolton) J. Schrot., Fomitopsis rosea (Alb. \& Schwein.) P. Karst, G. applanatum (Persoon) Patouillard, Ganoderma lucidum (Curtis) P. Karst., Lenzites elegans (Spreng.) Pat., Microporus xanthopus (Fr.) Kuntze, and Polyporus pinisitus. In vitro methods of antibacterial evaluation against Staphylococcus aureus and antioxidant assessment via 2,2-diphenyl-1-picrylhydrazyl (DPPH) scavenging were performed using the mushroom extracts to determine the species with potential bioactive molecules of pharmaceutical importance.

\section{MATERIALS AND METHODS}

\section{Collection of mushroom species}

The mushroom species were collected from three sites Sitio Pastolan, Hermosa from July to December of 2016. The map coordinate of the study site is $14^{\circ} 50^{\prime} 26.29^{\prime \prime} \mathrm{N}$ and $120^{\circ} 20^{\prime} 47.17^{\prime \prime} \mathrm{E}$. Collected macrofungi were wrapped in newspaper. Each were labeled accordingly and voucher specimen were submitted to the National Museum of the Philippines for taxonomic identification.

\section{Preparation of ethanol mushroom extracts}

Macrofungi were weighed separately using a toploading balance. They were dried in the oven overnight at $40^{\circ} \mathrm{C}$ and were air-dried after for seven days. They were washed with distilled water and cut into small pieces. About 150 grams of each macrofungus were soaked in $500 \mathrm{~mL}$ of $95 \%$ ethanol for five days. Filtration was done using Whatman filter paper No. 1. The supernatant was concentrated by a rotary evaporator at $40^{\circ} \mathrm{C}$. Stock solutions were prepared by dissolving the dried extracts in $1 \%$ DMSO to a

Cite this article: Gaylan CM, Estebal JC, Tantengco OAG, Ragragio EM. Anti-Staphylococcal and Antioxidant Properties of Crude Ethanolic Extracts of Macrofungi Collected from the Philippines. Pharmacog J. 2018;10(1):106-9. 
concentration of $100 \mathrm{mg} / \mathrm{mL}$ after collection. The extracts were stored at $4^{\circ} \mathrm{C}$ for subsequent use.

\section{Test microorganism}

Staphylococcus aureus (ATCC 25923) was retrieved from the Department of Medical Microbiology, College of Public Health in the University of the Philippines Manila.

\section{Kirby-bauer disk diffusion assay}

A $24 \mathrm{~h}$ culture of $S$. aureus was prepared prior to the methods of disk diffusion assay. It was inoculated in sterile Brain Heart Infusion broth with the turbidity adjusted to $0.5 \mathrm{McF}$ arland standard of approximately $1.5 \times 10^{8} \mathrm{CFU} / \mathrm{mL}$. A volume of the inoculum was swabbed on MuellerHinton agar plate using a sterile cotton swab within 15 minutes after standardization. Twenty microliters $(20 \mu \mathrm{L})$ of the crude ethanolic macrofungal extract were loaded on sterile $6 \mathrm{~mm}$ paper disks and were placed on the agar plates. Ciprofloxacin $(5 \mu \mathrm{g})$ was used as the positive control while $95 \%$ ethanol and $1 \%$ DMSO were used as negative controls. Incubation of the plates were done at $35 \pm 2^{\circ} \mathrm{C}$ for 16 to $24 \mathrm{~h}$. The setup was done in triplicates and the diameters of zone of inhibition were measured in millimeters using a Vernier caliper.

\section{Broth microdilution method}

The minimum inhibitory concentration at which 50\% of the bacteria were inhibited $\left(\mathrm{MIC}_{50}\right.$ ) of the macrofungi was determined by broth microdilution method according to Clinical Laboratory Standard Institute M07-A9 (2012). Two-fold dilution of the macrofungal extracts with a starting concentration of $100 \mathrm{mg} / \mathrm{mL}$ was done using Mueller-Hinton broth in Wasserman tubes generating concentrations from $19.5 \mu \mathrm{g} / \mathrm{mL}$ to $10000 \mu \mathrm{g} / \mathrm{mL}$. One hundred microliters $(100 \mu \mathrm{L})$ of each macrofungal extract concentration was transferred to its designated plates on the 96-well micro plate.

The inoculum was prepared as described in the Kirby-Bauer disk diffusion method. A 1:20 dilution of the suspension was made using MHB as the diluent. Ten microliters $(10 \mu \mathrm{L})$ of the inoculum was added to each of the wells. Media were mixed and the trays were incubated at $35 \pm 2^{\circ} \mathrm{C}$ for 16 to $24 \mathrm{~h}$. Reading of absorbance values was done using the ELISA micro plate reader. Controls include a reference drug control and a negative control blank containing no bacterial inoculum. Extracts with $1 \%$ DMSO, $95 \%$ ethanol and MHB were also used as controls. Determining the $\mathrm{MIC}_{50}$ required the use of the formula:

$$
\mathrm{MIC}_{50}=[(A c-A s) / A b] \times 100
$$

Where $A c$ is the absorbance of the blank control, $A s$ is the absorbance with the extract and $A b$ is the absorbance of the MHB control. The lowest concentration which had a percentage of at most $50 \%$ served as the $\mathrm{MIC}_{50}$ of the extract.

\section{DPPH assay}

Four hundred micrograms $(400 \mu \mathrm{g})$ of the dried extracts was weighed using an analytical balance and was dissolved in $1 \mathrm{~mL}$ of $95 \%$ ethanol in a microcentrifuge tube. Two hundred microliters $(200 \mu \mathrm{L})$ of the extract was added to the first lane of the 96 -wells microplate with $100 \mu \mathrm{L}$ of $95 \%$ ethanol in the succeeding lanes. Two-fold dilution was done using a multichannel pipette discarding the last $100 \mu \mathrm{L}$ from the last lane. Addition of $100 \mu \mathrm{L}$ of $0.2 \mathrm{mM}$ DPPH radical was done to each well producing a range of concentration from $200 \mu \mathrm{g} / \mathrm{mL}$ to $0.1 \mu \mathrm{g} / \mathrm{mL}$ of the extract. Blank controls were also done. The mixture was shaken using a vortex mixer for 30 minutes before subjecting to the spectrophotometer set at $515 \mathrm{~nm}$ for absorbance readings. The scavenging activity (SA) (\%) of the extracts on the DPPH radical was computed using the formula:

$$
\mathrm{SA}=[(A c-A s) / A c] \times 100
$$

Where $A c$ is the absorbance of the control and $A s$ is the absorbance with the extract. Tests were done in triplicates and a calibration curve was constructed with ascorbic acid as the standard.

\section{Data analysis}

Data were analyzed using the SPSS program and GraphPad Prism. Half maximal effective concentration $\left(\mathrm{EC}_{50}\right)$ was also computed from the SA values of each ethanolic extract. Shapiro-Wilk test was performed to determine if the data were in normal distribution. Mann-Whitney's test was done to determine which sample extract has significantly different antimicrobial activity when paired with ciprofloxacin. The test was also done to assess differences between the $\mathrm{EC}_{50}$ values of each extract against the ascorbic acid standard. Differences with p-value of less than 0.05 $(P<0.05)$ were considered as statistically different.

\section{RESULTS}

Diameters of zone of inhibitions from the activities of the mushroom extracts are shown in Table 1. G. applanatum, G. lucidum and P. pinisitus exhibited zones of inhibition ranging from $6.55 \pm 0.23 \mathrm{~mm}$ to $7.43 \pm 0.29$ $\mathrm{mm}$ against $S$. aureus. The rest of the macrofungi did not exhibit antistaphylococcal activity.

D. confragosa, F. rosea, G. lucidum, M. xanthopus and P. pinisitus showed antimicrobial activities against $S$. aureus with an $\mathrm{MIC}_{50}$ ranging from $1250 \mu \mathrm{g} / \mathrm{mL}$ to $10000 \mu \mathrm{g} / \mathrm{mL}$ (Table 2). Only G. applanatum and the L. elegans showed no significant $\mathrm{MIC}_{50}$ values against $S$. aureus.

The radical-scavenging effects of the samples were observed by the capacity to decrease the absorbance of the DPPH solution at $515 \mathrm{~nm}$. $\mathrm{EC}_{50}$ values of the crude ethanolic macrofungal extracts are shown in Figure 2. In general, extracts exhibited DPPH radical scavenging as most have an activity of above $50 \%$ at $200 \mu \mathrm{g} / \mathrm{mL}(\log$ [extract]: 2.3$)$. Notable effective

Table $1:$ Mean \pm SEM diameters of zone of inhibition $(\mathrm{mm})$ of crude ethanolic macrofungal extracts against $S$. aureus.

\begin{tabular}{cc}
\hline Mushroom Extract & S. aureus \\
\hline Daedaleopsis confragosa & - \\
Fomitopsis rosea & - \\
Ganoderma applanatum & $7.12 \pm 0.88$ \\
Ganoderma lucidum & $7.43 \pm 0.29$ \\
Lenzites elegans & - \\
Microporus xanthopus & - \\
Polyporus pinistus & $6.55 \pm 0.23$ \\
95\% Ethanol & - \\
1\% DMSO & - \\
Ciprofloxacin & $24.28 \pm 0.15(\mathrm{~S})$ \\
\hline
\end{tabular}

Table 2 : $\mathrm{MIC}_{50}(\mu \mathrm{g} / \mathrm{mL})$ of ethanolic extracts from eight mushrooms against $S$. aureus

\begin{tabular}{cc}
\hline Mushroom Extracts & S. aureus \\
\hline Daedaleopsis confragosa & 1250 \\
Fomitopsis rosea & 2500 \\
Ganoderma applanatum & - \\
Ganoderma lucidum & 10000 \\
Lenzites elegans & - \\
Microporus xanthopus & 2500 \\
Polyporus pinistus & 2500 \\
\hline
\end{tabular}




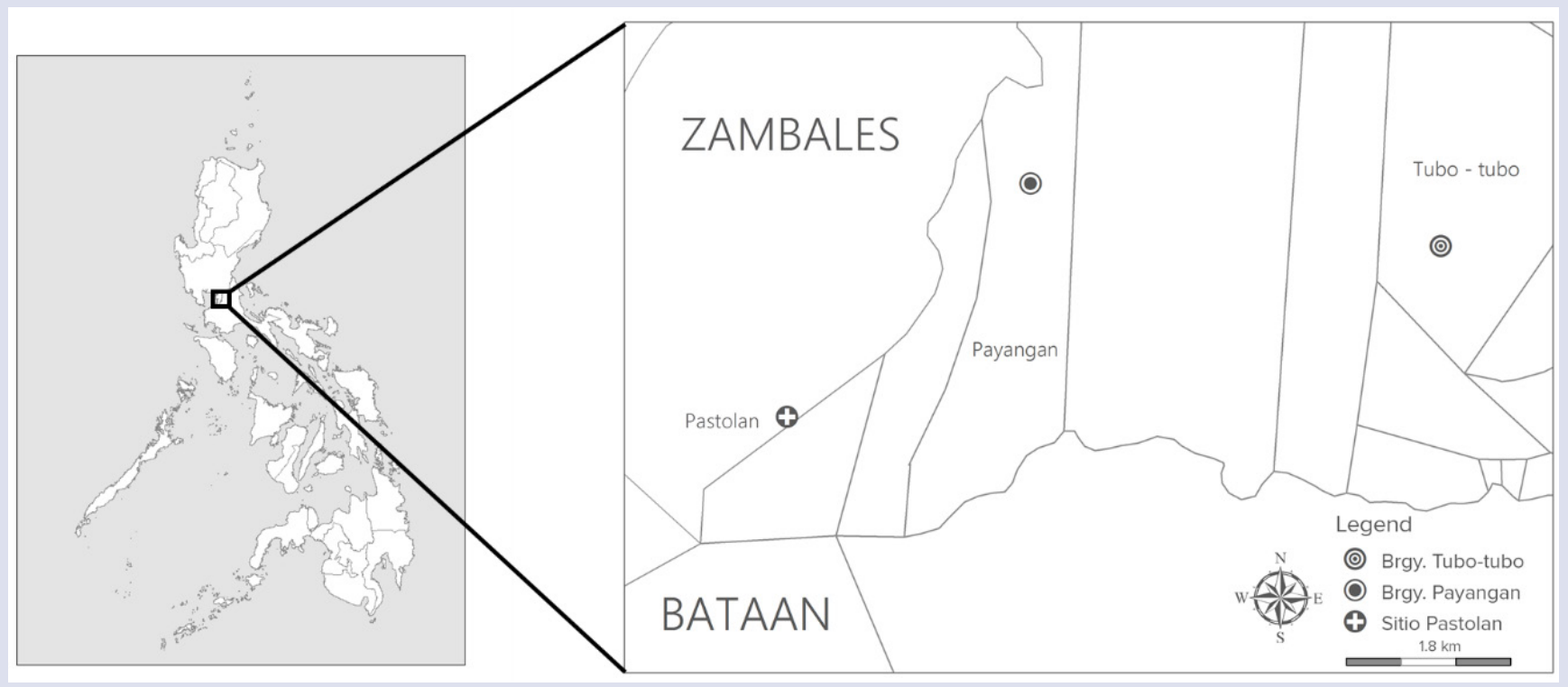

Figure 1: The map shows the Bataan province, Municipality of Hermosa, Bataan Province, Island of Luzon.

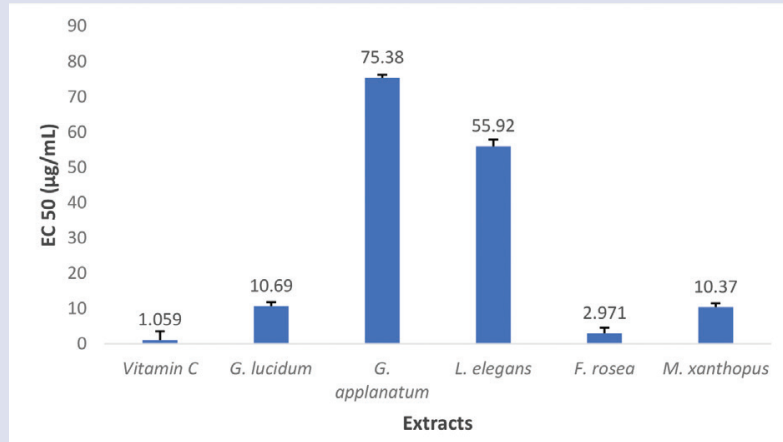

Figure 2: DPPH radical scavenging activities of macrofungal extracts from Bataan, Philippines. Each value was expressed as mean $\pm \operatorname{SEM}(n=3)$.

antioxidant activities due to low to moderate $\mathrm{EC}_{50}$ values include $F$. rosea, G. applanatum, G.lucidum, M. xanthopus, with F. rosea having the highest antioxidant activity among all the extracts tested $(3.0 \mu \mathrm{g} / \mathrm{mL})$.

\section{DISCUSSION}

There were few published literatures on the mushrooms species present in the Philippines. There were also few researches on the antimicrobial activity of mushrooms species in the country. ${ }^{8}$ Majority of the antimicrobial activity screening studies in the Philippines used terrestrial plants. Providing baseline information on the bioactivities of these mushroom species will contribute knowledge on macrofungi in the Philippines as it is not well documented at present. ${ }^{7}$

Mushrooms are advantageous as source of bioactive compounds over plants because their fruiting body can be produced in shorter period of time. Different wild mushrooms have been previously reported to have high antimicrobial and antioxidant activity. Phytochemical analysis from previous studies have shown that antioxidants found in mushrooms are mainly from phenolic compounds (phenolic acids and flavonoids), tocopherols, ascorbic acid and carotenoids. ${ }^{9}$

The minimal to no zone of inhibition against $S$. aureus did not necessarily mean the absence of antimicrobial activity of the macrofungal extracts. Diffusion assay is not suited to crude extracts with less polar compounds because they are hardly soluble in water and their hydrophobic nature inhibits the diffusion of the extract through the agar media. ${ }^{10}$

This limitation of diffusion was addressed by broth microdilution method showing better antibacterial activity.The results of broth microdilution assay revealed higher antimicrobial activity compared to Kirby Bauer disc diffusion assay. D. confragosa showed the highest $\mathrm{MIC}_{50}$ against $S$. aureus based on this study. This was supported by previous literature which showed that $D$. confragosa had $\mathrm{MIC}_{50}$ value of $5 \mathrm{mg} / \mathrm{mL}$ against $S$. aureus. Previous studies also showed that $D$. confragosa contains tannins and flavonoids which are both major classes of antimicrobial compounds present in macrofungi. ${ }^{2,11,12}$

F. rosea, G. lucidum, G. applanatum and $M$. xanthopus have statistically comparable DPPH scavenging effects $(p<0.05)$ to the standard vitamin C. No correlation was observed between the antioxidant and antibacterial properties of the macrofungi tested. Based on previous studies, F. rosea contains triterpenes but it has no antiradical activity against DPPH radicals. ${ }^{13}$ It is possible that other phytochemicals present in F. rosea is responsible for the excellent antioxidant activity obtained in this study. Exopolysaccharisdes have been previously isolated from G. lucidum which exhibited antioxidant properties. ${ }^{14}$ Previous study has shown that polysaccharides from G. applanatum has antioxidant activity. ${ }^{15}$ Previous reports on $M$. xanthopus showed it contains high amount of ascorbic acid and antioxidant activity. ${ }^{16}$

\section{CONCLUSION}

D. confragosa, F. rosea, G. lucidum, M. xanthopus and P. pinisitus showed antimicrobial activities against $S$. aureus with $\mathrm{MIC}_{50}$ ranging from $1250 \mu \mathrm{g} / \mathrm{mL}$ to $10000 \mu \mathrm{g} / \mathrm{mL}$. F. rosea, G. lucidum, G. applanatum and $M$. xanthopus have statistically comparable DPPH scavenging effects $(p<0.05)$ to the standard vitamin $C$. These Philippine macrofungi can be further explored as potential sources of antibacterial and antioxidant compounds. Isolation of these compounds in further studies can lead to 
the eventual clinical application of mushrooms as agents against bacteria and oxidative stress.

\section{ACKNOWLEDGEMENT}

This work was financed by the UP Manila National Institutes of Health Faculty Research Grant (Project Code: NIH 2015-007).

\section{CONFLICT OF INTEREST}

The authors declare no conflict of interest. The funding sponsors had no role in the design of the study; in the collection, analyses, or interpretation of data; in the writing of the manuscript, and in the decision to publish the results.

\section{ABBREVIATION USED}

DMSO: Dimethyl sulfoxide; DPPH: 2,2-diphenyl-1-picrylhydrazyl; EC $_{50}$ :Effective concentration 50.

\section{REFERENCES}

1. Money NP, Gadd GM. Are mushrooms medicinal? Fungal Biol. 2016;120(4):449-53.

2. Nowacka N, Nowak R, Drozd M, Olech M, Los R. Antibacterial, Antiradical Potential and Phenolic Compounds of Thirty-One Polish Mushrooms. PLoS One. 2015;10(10):1-13

3. Tamrakar S, Bang H, Marina T, Satoru N. Antioxidative activities of 62 wild mushrooms from Nepal and the phenolic profile of some selected species. J Nat Med. 2016;70(4):769-79

4. Yu J, Sun R, Zhao Z, Wang Y. Auricularia polytricha polysaccharides induce cell cycle arrest and apoptosis in human lung cancer A549 cells. Int J Biol Macromol. 2014;68:67-71.
GRAPHICAL ABSTRACT

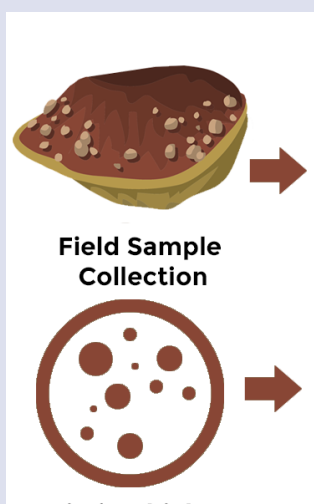

Antimicrobial Assays (Kirby Bauer and MIC)

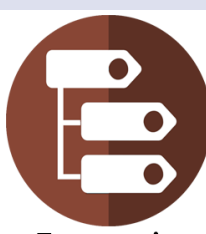

Taxonomic Identification

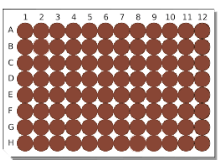

Antioxidant Assay (DPPH)

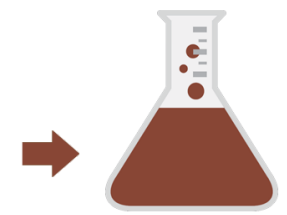

Crude Extraction and Rotary Evaporation

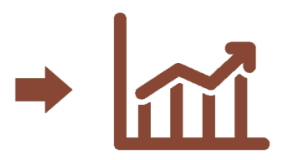

Statistical Analysis
5. Waithaka PN, Gathuru EM, Githaiga BM, Onkoba KM. Antimicrobial Activity of Mushroom (Agaricus Bisporus) and Fungal (Trametes Gibbosa) Extracts from Mushrooms and Fungi of Egerton Main Campus, Njoro Kenya. J Biomed Sci. 2017;6(3):1-6.

6. Sanchez C. Reactive oxygen species and antioxidant properties from mushrooms. Synth Syst Biotechnol. 2017;2:13-22

7. Tadiosa E, Briones R. Fungi of Taal Volcano Protected Landscape, Southern Luzon, Philippines. Asian Sci J. 2013;4(1):46-64.

8. Kalaw S, Albinto R. Functional activities of Philippine wild strain of Coprinus comatus (O.F. Müll.: Fr .) Pers and Pleurotus cystidiosus O . K. Miller grown on rice straw based substrate formulation. Mycosphere. 2014;5(5):646-55.

9. Ferreira I, Barros L, Abreu R. Antioxidants in Wild Mushrooms. Curr Med Chem. 2009;16(12):1543-60.

10. Klancnik A, Piskernik S, Jersek B, Mozina SS. Evaluation of diffusion and dilution methods to determine the antibacterial activity of plant extracts. J Microbio Methods. 2010;81(2):121-6.

11. Okwulehie IC, Okorie DO, Egekonye TA. Phytochemical, Proximate, Vitamins, Minerals and Heavy Metals Composition of Two Indigenous Mushrooms (Daedaleopsis confragosa, (Polyporaceae) and Russule girolle (Cantharellus cibarius). IOSR J Pharm Biol Sci. 2014;9(3):65-71.

12. Cowan MM. Plant products as antimicrobial agents. Clin Microbiol Rev. 1999; 12(4):564-82.

13. Popova M, Trusheva B, Gyosheva M, Tsvetkova I, Bankova V. Antibacterial triterpenes from the threatened wood-decay fungus Fomitopsis rosea. Fitoterapia. 2009;80(5):263-6.

14. Mahendran S, Anandapandian T, Shankar T, Chellaram C, Vijayabaskar P. Antioxidant Properties of Ganoderma lucidum Crude Exopolysaccharide. Indian J Innov Dev. 2012;1(8):1-6.

15. Zhong-hua L, Xiao-ge H, Jin-hui Z, Le H. Liquid Fermentation of Ganoderma applanatum and Antioxidant Activity of Exopolysaccharides. Open Biomed Eng J. 2015;9:224-7.

16. Tripathy SS, Rajoriya A, Gupta N. Wild Mushrooms of Odisha: Prospective Candidates of Antioxidant Sources. Adv Plants Agric Res. 2014;1(4):2-7.

\section{ABOUT AUTHORS}

Christine May D. Gaylan: BS Biology graduate at the Department of Biology, College of Arts and Sciences, University of the Philippines Manila, Philippines.

John Carlo Estebal: BS Biology graduate at the Department of Biology, College of Arts and Sciences, University of the Philippines Manila, Philippines.

Ourlad Alzeus G. Tantengco: MD-PhD in Molecular Medicine student at the College of Medicine, University of the Philippines Manila, Philippines.

Elena M. Ragragio: Associate Professor and Chairman at the Department of Biology, College of Arts and Sciences, University of the Philippines Manila, Philippines.

Cite this article: Gaylan CM, Estebal JC, Tantengco OAG, Ragragio EM. Anti-Staphylococcal and Antioxidant Properties of Crude Ethanolic Extracts of Macrofungi Collected from the Philippines. Pharmacog J. 2018;10(1):106-9. 